\title{
Plasma Triglyceride Concentration and Plasma Free Fatty Acid Changes in Response to Norepinephrine in $\operatorname{Man} *$
}

\author{
P. J. Nestel \\ (From the University of Melbourne Department of Medicine, Royal Melbourne Hospital, \\ Melbourne, Victoria, Australia)
}

Hypertriglyceridemia is frequently observed in subjects with coronary artery disease and is particularly common in young males $(1,2)$. A number of factors undoubtedly contribute to the increased levels of plasma triglycerides; among these, the role of exogenous dietary fat has been established (3). The magnitude of endogenous triglyceride synthesis has not been measured in patients with hypertriglyceridemia, although it is known that in fasting man, plasma triglycerides are derived from free fatty acids (FFA) (4). Since the flux of FFA from adipose tissue stores is, to a large extent, determined by the activity of the sympathetic nervous system (5), it seems possible that the level of plasma triglycerides in a given individual might be related to the responsiveness of the adipose tissue to catecholamines.

This paper presents evidence to support this hypothesis. The increment in plasma FFA in response to a standard infusion of norepinephrine has been measured in subjects with and without coronary artery disease and related to their plasma triglyceride levels. The depression of plasma FFA by nicotinic acid has also been measured and related to the initial plasma FFA and triglyceride levels, since nicotinic acid has been shown to inhibit catecholamine-induced mobilization of FFA (6).

\section{Materials and Methods}

Seventeen men with coronary artery disease, ages 34 to 49 (mean age, 44), and another group of 8 men, ages 32 to 53 (mean age, 43), were studied. The subjects with coronary artery disease had survived a myocardial infarction at least 3 months previously and were leading a normal ambulant life at the time of the investiga-

* Submitted for publication July 8, 1963; accepted September 19, 1963.

Supported by a grant from the National Heart Foundation of Australia. tion. The other group consisted of men attending the hospital for minor surgical complaints who were otherwise healthy and ambulant. All the men were therefore familiar with such hospital procedures as venipuncture. Patients with obviously hyperlipemic plasma were excluded.

The subjects, who had not smoked since the previous day, were studied after an overnight fast. After the subjects had rested for half an hour, an indwelling catheter was placed into a vein, and the first sample of blood was obtained after a further half-hour. Three control samples of blood were usually obtained during the following 30 minutes. Norepinephrine was infused at a constant rate of $0.2 \mu \mathrm{g}$ per $\mathrm{kg}$ per minute for $15 \mathrm{~min}$ utes. Further samples of blood were collected at the end of the infusion and 5, 15, 30, and 45 minutes later. (In preliminary studies peak FFA levels were reached 5 minutes after the end of the infusion and had returned to preinfusion levels within 45 minutes.)

Further control samples were obtained when the FFA levels had returned to basal levels, and $200 \mathrm{mg}$ nicotinic acid was then given by mouth to 15 of the subjects with coronary artery disease. Blood was collected 30 and 60 minutes later, because the observation had earlier been made that FFA decreases steadily during the first hour after the oral administration of nicotinic acid.

Blood was collected into iced, heparinized tubes and the plasma separated at $4^{\circ} \mathrm{C}$ by centrifuging for 10 minutes at 2,500 rpm. FFA were measured according to the technique of Dole (7), plasma triglycerides by the method of Van Handel and Zilversmit (8), and plasma total cholesterol by the method of Abell, Levy, Brodie, and Kendall (9).

\section{Results}

Norepinephrine infusions in patients with coronary heart disease. The main initial plasma FFA concentration for patients with coronary heart disease was $420 \mu \mathrm{Eq}$ per L. In general, the first of the three preinfusion samples of plasma contained a higher concentration of FFA, but the second and third samples, obtained 20 and 30 minutes after the insertion of the indwelling catheter, were usually almost identical. The initial FFA 
TABLE I

Plasma concentrations of FFA, triglyceride, and cholesterol in fasting subjects, and increments in plasma FFA and in systolic arterial pressure in response to norepinephrine

\begin{tabular}{|c|c|c|c|c|c|c|}
\hline \multirow[b]{2}{*}{ Subject } & \multicolumn{3}{|c|}{ Initial plasma concentration } & \multicolumn{2}{|c|}{ Increment in FFA } & \multirow{2}{*}{$\begin{array}{l}\text { Rise in } \\
\text { sys- } \\
\text { tolic } \\
\text { blood } \\
\text { pressure }\end{array}$} \\
\hline & $\begin{array}{c}\text { Triglyc- } \\
\text { eride }\end{array}$ & $\begin{array}{l}\text { Choles- } \\
\text { terol }\end{array}$ & FFA & $\begin{array}{c}\begin{array}{c}\text { Abso- } \\
\text { lute }\end{array} \\
\text {. }\end{array}$ & $\begin{array}{c}\text { Percen- } \\
\text { tile }\end{array}$ & \\
\hline Coronary heart disease & $m g / 100 m l$ & $m g / 100 m l$ & $\mu E q / L$ & $\mu E q / L$ & $\%$ & $m m \mathrm{Hg}$ \\
\hline 1 & $\begin{array}{l}58 \\
82\end{array}$ & $\begin{array}{l}262 \\
247\end{array}$ & $\begin{array}{l}480 \\
410\end{array}$ & $\begin{array}{l}220 \\
440\end{array}$ & $\begin{array}{r}28 \\
107\end{array}$ & $\begin{array}{l}25 \\
21\end{array}$ \\
\hline 3 & 94 & 247 & 360 & 340 & 94 & 2 \\
\hline 4 & 97 & 262 & 370 & 260 & 67 & 14 \\
\hline 5 & 104 & 304 & 350 & 360 & 102 & 50 \\
\hline 6 & 111 & 351 & 550 & 470 & 85 & 30 \\
\hline 7 & 113 & 219 & 460 & 210 & 46 & 15 \\
\hline 8 & 113 & 315 & 380 & 540 & 142 & 40 \\
\hline 9 & 128 & 295 & 210 & 490 & 235 & 45 \\
\hline 10 & 143 & 310 & 200 & 770 & 370 & 80 \\
\hline 11 & 163 & 283 & 370 & 610 & 165 & 30 \\
\hline 12 & 167 & 300 & 300 & 350 & 114 & 80 \\
\hline 13 & 169 & 276 & 490 & 780 & 155 & 25 \\
\hline 14 & 202 & 253 & 480 & 580 & 120 & 8 \\
\hline 15 & 240 & 346 & 500 & 700 & 140 & 40 \\
\hline 16 & 269 & 375 & 810 & 1,030 & 130 & 39 \\
\hline 17 & 285 & 307 & 350 & 610 & 175 & 20 \\
\hline Mean & 149 & 291 & 420 & 515 & 130 & 33 \\
\hline \multicolumn{7}{|l|}{ Controls } \\
\hline 18 & 95 & 191 & 420 & 380 & 90 & 25 \\
\hline 19 & 84 & 167 & 460 & 480 & 104 & 35 \\
\hline 20 & 145 & 288 & 370 & 640 & 173 & 30 \\
\hline 21 & 160 & 276 & 400 & 800 & 200 & 25 \\
\hline 22 & 150 & 310 & 500 & 900 & 180 & 80 \\
\hline 23 & 95 & 184 & 480 & 410 & 85 & 40 \\
\hline 24 & 100 & 220 & 410 & 700 & 170 & 40 \\
\hline 25 & 115 & 250 & 320 & 610 & 190 & 60 \\
\hline Mean & 118 & 236 & 420 & 615 & 150 & 42 \\
\hline
\end{tabular}

concentration was therefore considered to have reached a basal level. The mean plasma triglyceride and cholesterol concentrations for the patient group were $149 \mathrm{mg}$ and $291 \mathrm{mg}$ per $100 \mathrm{ml}$, respectively. There were few subjective symptoms, but 2 patients complained of slight and transient tightness in the chest.

There was a consistent pattern in the FFA response to the norepinephrine infusions. The sample of plasma obtained 5 minutes after the cessation of the infusion contained a higher concentration of FFA than either the immediate or the 15-minute postinfusion samples in 15 of 17 experiments ; in the remaining 2 , the FFA concentrations in the 15-minute samples were slightly higher than those in the 5-minute samples. The 5-minute sample has therefore been taken to represent the peak FFA response, and the rise above the preinfusion level has been expressed in terms of absolute and percentile increments (Table I). The mean absolute increment for the patient group was $515 \mu \mathrm{Eq}$ per $\mathrm{L}$, or a mean increase of $130 \%$.

A rise in systolic and diastolic pressure was invariably recorded, although a significant slowing of the pulse rate was uncommon. The mean rise in systolic arterial pressure was $33 \mathrm{~mm} \mathrm{Hg}$ (Table I).

The relationship between the plasma triglyceride concentration and the absolute increments in FFA is shown in Figure 1 . The calculated regression line shows the relationship to be highly significant $(p=<0.001 ; r=0.77)$. There was also a significant relationship between plasma cholesterol concentration and increment in FFA ( $p=$ $<0.005 ; r=0.61$ (Figure 2). The initial FFA concentration was not significantly related to either the triglyceride concentration or to the in- 


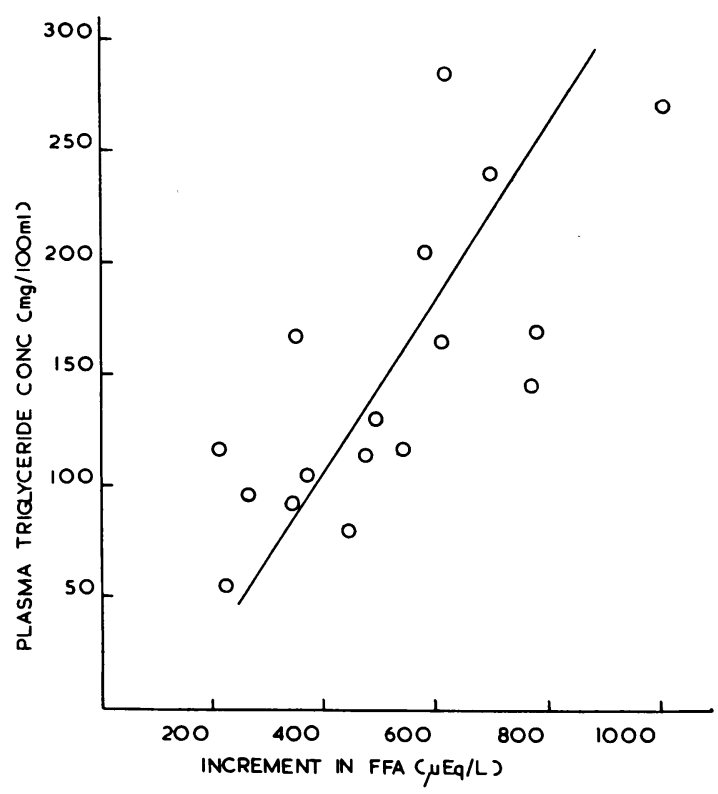

Fig. 1. Relationship between plasma triglyceride CONCENTRATION AND ABSOLUTE INCREMENT IN PLASMA FFA IN RESPONSE TO NOREPINEPHRINE IN 17 PATIENTS WITH CORONARY HEART DISEASE.

crement in FFA. There was also no relationship between the increment in FFA and the rise in systolic arterial pressure.

Norepinephrine infusions in subjects without coronary heart disease. The mean plasma concentrations of FFA, triglyceride, and cholesterol were found to be $420 \mu \mathrm{Eq}$ per L, $118 \mathrm{mg}$ per $100 \mathrm{ml}$,

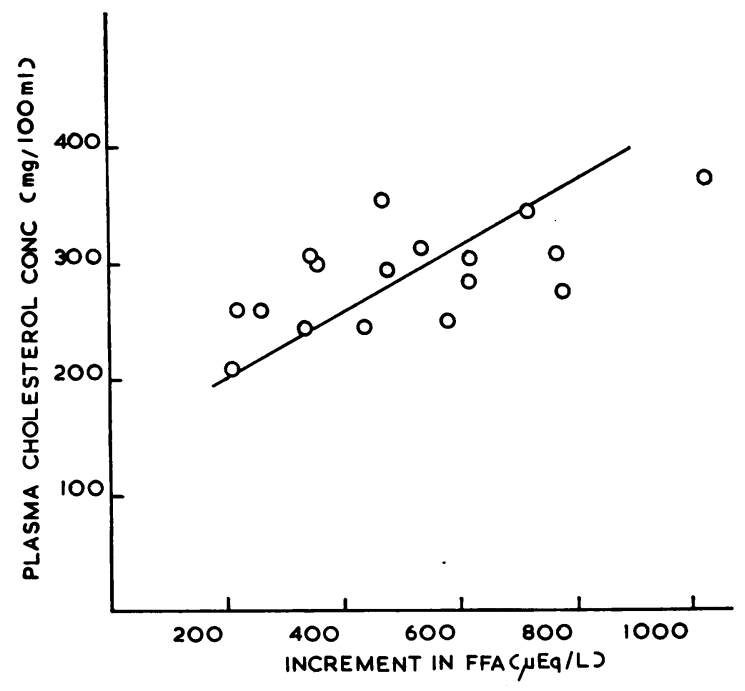

Fig. 2. Relationship between plasma total choLESTEROL CONCENTRATION AND ABSOLUTE INCREMENT IN PLASMa FFA AS DESCRIBEd IN Figure 1.

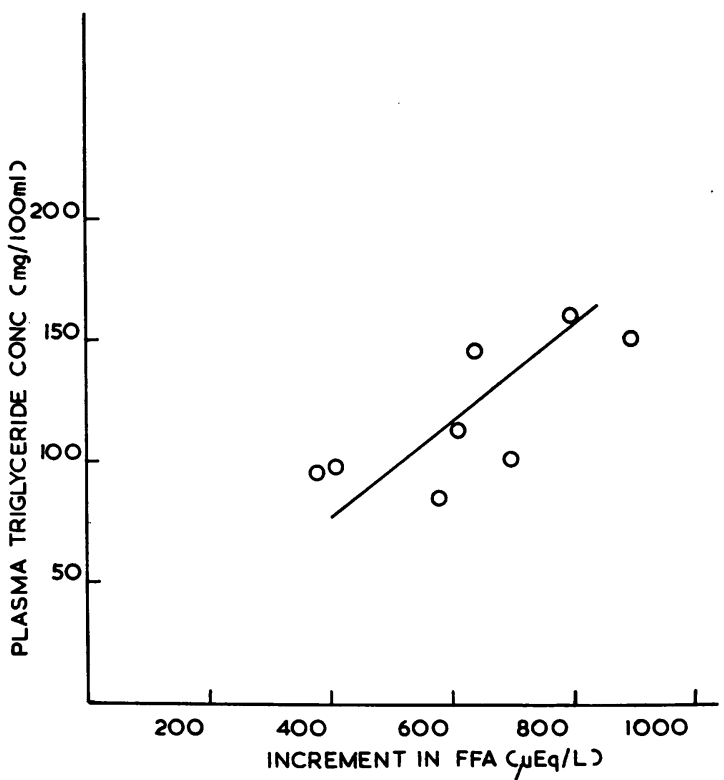

Fig. 3. Relationship BetweEn PLASMa tRIGlyCERIDE CONCENTRATION AND ABSOLUTE INCREMENT IN PLASMA FFA IN RESPONSE TO NOREPINEPHRINE IN 8 SUBJECTS WITHOUT CORONARY HEART DISEASE.

and $236 \mathrm{mg}$ per $100 \mathrm{ml}$, respectively. A comparison between these levels and those found in the patient group is not justified, since the latter group was not chosen at random but because of their plasma triglyceride concentrations.

In the control group, the mean absolute and percentile increments in FFA were $615 \mu \mathrm{Eq}$ per

TABLE II

Plasma FFA concentration and the absolute fall in FFA 1 hour after the ingestion of $200 \mathrm{mg}$ nicotinic acid by fasting subjects

\begin{tabular}{rcc}
\hline Subject & $\begin{array}{c}\text { Initial } \\
\text { plasma } \\
\text { FFA con- } \\
\text { centration }\end{array}$ & $\begin{array}{c}\text { Absolute } \\
\text { fall } \\
\text { in FFA }\end{array}$ \\
\hline & $\mu E q / L$ & $\mu E q / L$ \\
1 & 210 & 10 \\
2 & 210 & 60 \\
3 & 300 & 130 \\
4 & 550 & 170 \\
5 & 350 & 200 \\
6 & 340 & 210 \\
7 & 360 & 210 \\
8 & 410 & 230 \\
9 & 350 & 260 \\
10 & 500 & 280 \\
11 & 460 & 290 \\
12 & 390 & 300 \\
13 & 480 & 300 \\
14 & 580 & 410 \\
15 & 810 & 460 \\
\hline
\end{tabular}




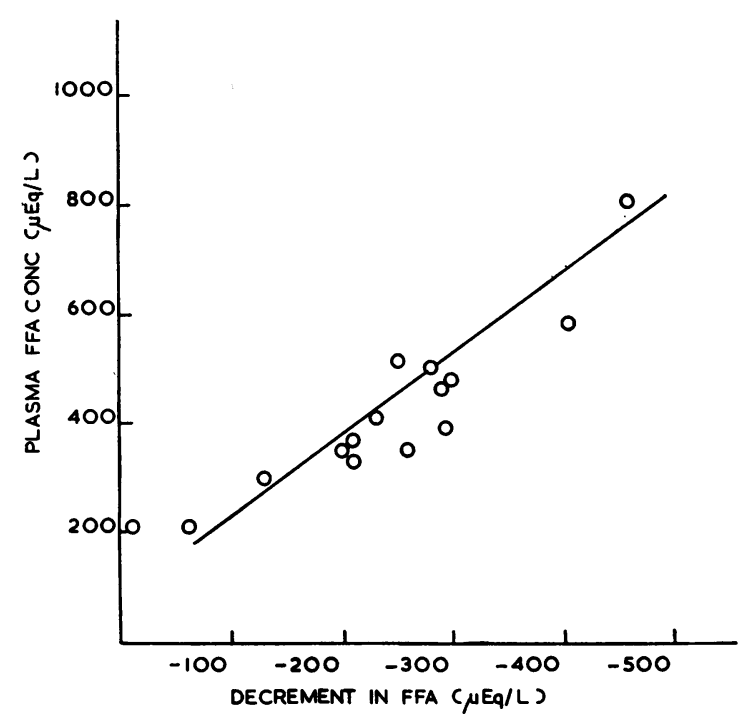

Fig. 4. Relationship between plasma basal FFA CONCENTRATION AND DECREMENT IN FFA AFTER INGESTION OF NICOTINIC ACID IN 15 PATIENTS WITH CORONARY HEART DISEASE.

$\mathrm{L}$ and $150 \%$, respectively. The mean rise in systolic pressure was $42 \mathrm{~mm} \mathrm{Hg}$. These findings did not differ significantly from those concerning the patient group. The relationship between the plasma triglyceride concentration and the absolute increment in FFA was significant ( $\mathrm{p}=<$ $0.005 ; \mathrm{r}=0.81$ ) (Figure 3).

Nicotinic acid study. Preliminary studies showed that the ingestion of $200 \mathrm{mg}$ of nicotinic acid produced an almost linear reduction in plasma FFA concentration, reaching a nadir in about 1 hour. A generalized flush began after about 20 minutes and persisted for from 20 minutes to as long as 2 hours. A reduction in FFA concentra-

TABLE III

Percentage of change in plasma FFA 5 minutes after infusions of norepinephrine,* before and after the ingestion of $200 \mathrm{mg}$ of nicotinic acid

\begin{tabular}{ccc}
\hline & \multicolumn{2}{c}{$\begin{array}{c}\text { Percentage of change in FFA } \\
\text { after norepinephrine infusion }\end{array}$} \\
\cline { 2 - 3 } Experiment & $\begin{array}{c}\text { Before } \\
\text { nicotinic } \\
\text { acid }\end{array}$ & $\begin{array}{c}\text { Atter } \\
\text { nicotinic } \\
\text { acid }\end{array}$ \\
\hline 1 & +64 & +3 \\
2 & +100 & +4 \\
3 & +109 & +27 \\
4 & +54 & -26 \\
5 & +64 & 0 \\
\hline
\end{tabular}

*Ten $\mu \mathrm{g}$ per minute for 10 minutes.

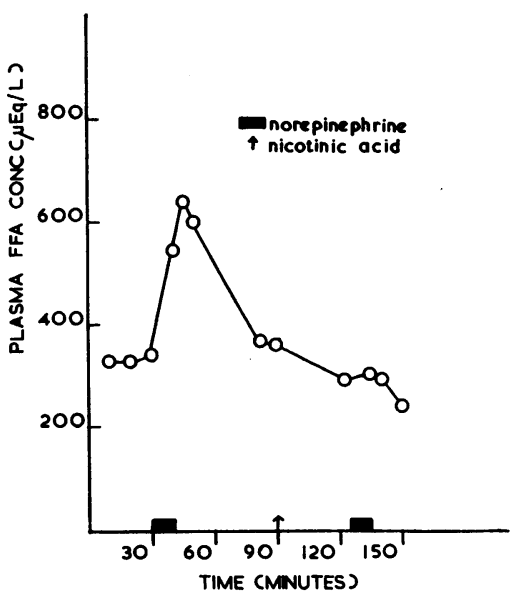

Fig. 5. Plasma FFA Response to NOREPinephrine (10 $\mu$ G PER MINUTE FOR 10 MINUTES) BEFORE AND AFTER INGESTION OF 200 MG NICOTINIC ACID.

tion was observed in all 15 experiments (Table II).

The reduction in FFA concentration at the end of 1 hour was significantly related to the initial FFA concentration $(\mathrm{p}=<0.001 ; \mathrm{r}=0.86)$ (Figure 4 ). The FFA concentration at 1 hour varied from 70 to $330 \mu \mathrm{Eq}$ per L, with a mean of $190 \mu \mathrm{Eq}$ per L. There was also a significant relationship between the decrement in FFA and the initial triglyceride concentration $(\mathrm{p}=<0.05 ; \mathrm{r}=$ $0.56)$.

The effect of pretreatment with nicotinic acid on FFA response to norepinephrine was studied in 5 normal subjects. Norepinephrine was infused at the rate of $10 \mu \mathrm{g}$ per minute for $10 \mathrm{~min}$ utes, and measurements of plasma FFA were made 5, 10, and 55 minutes later. Two hundred $\mathrm{mg}$ of nicotinic acid was given 1 hour later, and the norepinephrine infusion was repeated $30 \mathrm{~min}$ utes after the administration of nicotinic acid and obtaining of further samples of blood. In all individuals, pretreatment with nicotinic acid greatly modified the FFA increment after the infusion of norepinephrine (Table III, Figure 5).

\section{Discussion}

The results show a highly significant correlation between a fasting individual's plasma triglyceride concentration and the magnitude of FFA mobilization in response to norepinephrine. This correlation appears to be equally valid for healthy men and for patients with clinical coronary heart 
disease. It cannot be said with certainty that this increased responsiveness to norepinephrine is a major factor in determining an individual's plasma triglyceride concentration, since both may be related to a common underlying factor. There is, however, a great deal of evidence to support such a possibility.

Previous investigations have demonstrated that the activity of the sympathetic nervous system determines to a large extent the flow of FFA from adipose tissue (5), and that in the fasting state, FFA are the major precursors of plasma triglycerides (4). It has also been shown that prolonged systemic infusions of norepinephrine into dogs will result in fatty livers and elevation of plasma triglycerides (10), and that perfusion of rat livers with high concentrations of FFA stimulates hepatic synthesis of triglycerides, which are then secreted into the perfusing fluid (11).

Additional support for this hypothesis has been derived from nicotinic acid studies, in which a significant correlation was found between triglyceride levels of fasting subjects and FFA decrements after nicotinic acid administration. That FFA level was lowered by nicotinic acid has been shown previously (6). Additional observations demonstrate the role of the sympathetic nervous system in determining the level of FFA in blood: the prior administration of nicotinic acid will abolish or greatly reduce the FFA response to norepinephrine in man (Table III), and there is a close relationship between the initial concentration of plasma FFA and the fall in FFA after the ingestion of nicotinic acid (Figure 4).

Nicotinic acid generally reduced the plasma FFA level to a concentration of about $200 \mu \mathrm{Eq}$ per $\mathrm{L}$; this basal level is probably determined by factors other than the sympathetic nervous system. This may explain the absence of a correlation, in the fasting individual, between plasma FFA and triglyceride levels despite the presence of a significant correlation between fasting triglyceride concentration and that portion of the plasma FFA concentration that can be reduced by nicotinic acid.

A close correlation was also demonstrated between plasma cholesterol concentration and FFA response to norepinephrine. This probably reflects merely the close relationship between triglyceride and cholesterol concentrations, although FFA can provide carbon fragments that serve as precursors for cholesterol synthesis. Carlson and Orö have suggested that the hypocholesterolemic effect of nicotinic acid might be related to the inhibitory effect of this drug on catecholamineinduced mobilization of FFA (6).

Friedman, Rosenman, and Carroll have stated that plasma levels of cholesterol rise during periods of stress (12). Stressful situations are accompanied by the secretion of catecholamines and great increments in the concentration of plasma FFA (13). The suggestion has been made that patients with coronary heart disease react to a stressful situation with a greater mobilization of FFA than do normal subjects. $\mathrm{Pa}$ tients with coronary heart disease have been shown to have higher levels of plasma FFA than control subjects after the smoking of cigarettes (14) or an examination in mental arithmetic (15). Both procedures are known to induce secretion of catecholamines. The present experiments were not designed to confirm this particular question, since all subjects with and without coronary heart disease were given the same amount of norepinephrine. However, for those patients and control subjects whose triglyceride concentrations were similar, the FFA increments after norepinephrine infusion were somewhat higher in the controls. An interesting point is that the mean increment in FFA was slightly, although not significantly, greater in control subjects than in patients with coronary heart disease, despite the absence in the control group of subjects with very high triglyceride concentrations.

Changes in blood pressure were not related to the increments in FFA, agreeing with previous studies showing the independence of cardiovascular and FFA responses to norepinephrine (16).

\section{Summary}

The relationship in the fasting subject between the plasma triglyceride concentration and the magnitude of free fatty acid (FFA) mobilization in response to norepinephrine was investigated in 17 male patients with coronary heart disease and 8 control male subjects of similar age.

A highly significant relationship was found between the plasma triglyceride concentration and the absolute and percentile increments in FFA af- 
ter a 15-minute infusion of norepinephrine. This relationship applied to both groups of subjects. At any given plasma triglyceride level, however, the FFA response was somewhat greater in the control subject than in the patient with coronary heart disease.

The inhibitory effect of nicotinic acid on norepinephrine-induced mobilization of FFA was confirmed. In 15 subjects, the fall in plasma FFA after the ingestion of $200 \mathrm{mg}$ nicotinic acid was found to be significantly related to the basal level of FFA. This fall in FFA was also significantly related to the triglyceride concentration.

It is concluded that the activity of the sympathetic nervous system, by determining the magnitude of FFA flux, is a major factor in the regulation of the fasting plasma triglyceride concentration in man.

\section{References}

1. Albrink, M. J., J. W. Meigs, and E. B. Man. Serum lipids, hypertension and coronary artery disease. Amer. J. Med. 1961, 31, 4.

2. Carlson, L. A. Serum lipids in men with myocardial infarction. Acta med. scand. 1960, 167, 399.

3. Antonis, A., and I. Bersohn. Serum-triglyceride levels in South African Europeans and Bantu and in ischæmic heart-disease. Lancet 1960, 1, 998.

4. Havel, R. J. The conversion of plasma free fatty acids into triglycerides of plasma lipoprotein fractions in man. Metabolism 1961, 10, 1031.

5. Havel, R. J., and A. Goldfien. The role of the sympathetic nervous system in the metabolism of free fatty acids. J. Lipid Res. 1959, 1, 102.

6. Carlson, L. A., and L. Orö. The effect of nicotinic acid on plasma free fatty acids. Demonstration of a metabolic type of sympathicolysis. Acta med. scand. 1962, 172, 641.

7. Dole, V. P. A relation between non-esterified fatty acids in plasma and the metabolism of glucose. J. clin. Invest. 1956, 35, 150.

8. Van Handel, E., and D. B. Zilversmit. Micromethod for the direct determination of serum triglycerides. J. Lab. clin. Med. 1957, 50, 152.

9. Abell, L. L., B. Levy, B. B. Brodie, and F. E. Kendall. A simplified method for the estimation of total cholesterol in serum and demonstration of its specificity. J. biol. Chem. 1952, 195, 357.

10. Feigelson, E. B., W. W. Pfaff, A. Karmen, and D. Steinberg. The role of plasma free fatty acids in development of fatty liver. J. clin. Invest. 1961, 40, 2171.

11. Nestel, P. J., and D. Steinberg. Fate of palmitate and linoleate perfused through the isolated rat liver at high concentration. J. Lipid Res. 1963, 4, 461.

12. Friedman, M., R. H. Rosenman, and V. Carroll. Changes in the serum cholesterol and blood clotting time in men subjected to cyclic variation of occupational stress. Circulation, 1958, 17, 852.

13. Bogdonoff, M. D., E. H. Estes, Jr., and D. Trout. Acute effect of psychologic stimuli upon plasma non-esterified fatty acid level. Proc. Soc. exp. Biol. (N. Y.) 1959, 100, 503.

14. Kershbaum, A., S. Bellett, R. F. Caplan, and L. J. Feinberg. Effect of cigarette smoking on free fatty acids in patients with myocardial infarction (abstract). Circulation 1961, 24, 970.

15. Penick, S. B. Greater non-esterified fatty acid response to moderate challenge in men with coronary heart disease (abstract). Clin. Res. 1962, 10, 402.

16. Steinberg, D., P. J. Nestel, E. R. Buskirk, and R. H. Thompson. Relation between fat-mobilization and hypermetabolism induced by norepinephrine and triiodothyronine (abstract). J. clin. Invest. 1963, 42, 983. 